\title{
Efeito da protease sobre o coeficiente de metabolizabilidade dos nutrientes em frangos de corte
}

\author{
[Effect of protease on the metabolization coefficient of nutrients in broilers] \\ C.F.Q. Matias ${ }^{1}$, J.S.R. Rocha ${ }^{1}$, M.A. Pompeu ${ }^{1}$, R.C. Baião ${ }^{1}$, N.C. Baião ${ }^{2}$, L.J.C. Lara $^{2}$, \\ W.L.S. Clímaco ${ }^{1}$, L.F.P. Pereira ${ }^{1}$, E.O. Caldas ${ }^{1}$, M.P.F. Teixeira ${ }^{1}$, P.C. Cardeal $^{1}$ \\ ${ }^{1}$ Aluno de pós-graduação - Universidade Federal de Minas Gerais -UFMG - Belo Horizonte, MG \\ ${ }^{2}$ Escola de Veterinária - Universidade Federal de Minas Gerais - UFMG - Belo Horizonte, MG
}

\begin{abstract}
RESUMO
Avaliaram-se os efeitos da protease sobre o coeficiente de metabolizabilidade dos nutrientes em dietas contendo farinha de penas $(2,0 \%$ na fase inicial e 3,0\% na fase de crescimento) para frangos de corte machos, Cobb $^{\circledR}$, de um a 32 dias de idade. Foram alojadas 336 aves em gaiolas metálicas equipadas com bandeja para coleta total de excretas. Foi utilizado delineamento inteiramente ao acaso, em arranjo fatorial 2x2 (com e sem adição da enzima protease $0,05 \%$ e duas valorizações da matriz nutricional da enzima), sendo sete repetições por tratamento, de 12 aves cada. Observou-se, na fase inicial, maior CMPB $(\mathrm{P} \leq 0,05)$ para as aves que, independentemente da adição de protease, consumiram ração com valorização da matriz nutricional da enzima. Não houve efeito dos tratamentos sobre o CMMS e o CMEE $(\mathrm{P}>0,05)$. Na fase de crescimento, houve interação entre os tratamentos para as variáveis CMPB e CMEE. Os frangos alimentados com dieta valorizada sem adição de enzima (controle negativo) apresentaram melhores resultados $(\mathrm{P} \leq 0,05)$ para $\mathrm{CMPB}$ e CMEE. Nos tratamentos com enzima, o melhor CMEE $(\mathrm{P} \leq 0,05)$ foi obtido com o tratamento sem valorização da matriz nutricional (over the top). Conclui-se que níveis reduzidos e enzima sem valorização melhoram os coeficientes de metabolizabilidade dos nutrientes na fase adulta de frangos de corte.
\end{abstract}

Palavras-chave: coeficiente de metabolizabilidade, enzimas exógenas, frango de corte, protease

\begin{abstract}
This experiment aimed to evaluate the effects of protease on metabolization coefficient of nutrients, performance and slaughter yield from male Cobb ${ }^{\circledR}$ broilers fed diets with feather meal. Two experiments were carried out in a completely randomized design in a $2 \times 2$ factorial arrangement - with (0.05\%) or without enzyme addition $x$ considering or not the improvement of the nutritional value by protease, with seven replicates per treatment group. In experiment 1 the metabolization coefficient of dry matter (MCDM), crude protein (MCCP) and ether extract (MCEE) in initial (9-12-d-old) and growth (29-32-dold) phase was evaluated. In the initial phase it was observed that regardless of enzyme addition, broiler chickens fed a diet considering improvement in nutritional value had higher MCCP $(P \leq 0.05)$. However, $M C D M$ and MCEE were not affected $(P>0.05)$. In the growth phase, there were interactions between treatments for the variables MCCP and MCEE. The birds fed diets considering the improvement in nutritional value without enzyme (negative control) showed better results $(P \leq 0.05)$ for MCCP and $M C E E$. In the treatments with enzyme, the best MCEE $(P \leq 0.05)$ was observed in the treatment not considering the improvement in the nutritional value (over the top). Therefore, considering the improvement in the nutritional value and enzyme without considering the improvement in the nutritional value improves the coefficients of metabolization of nutrients in broiler chickens.
\end{abstract}

Keywords: metabolization coefficient, enzyme, broilers, protease

Recebido em 4 de agosto de 2014

Aceito em 23 de dezembro de 2014

E-mail: christianematias@gmail.com 


\section{INTRODUÇÃO}

O uso de enzimas exógenas tem sido considerado como alternativa para diminuir os custos de produção, principalmente por melhorar a eficiência de utilização de alimentos tradicionais e viabilizar o uso de matérias-primas alternativas, como as farinhas de origem animal.

Sabendo-se que em torno de $7 \%$ do peso corporal das aves é representado por suas penas e tomando-se como peso final médio das aves $2,5 \mathrm{~kg}$, estima-se que a quantidade de resíduos (penas) alcance $846 \mathrm{mil}$ toneladas/ano, viabilizando a produção de grandes quantidades de farinha (Holanda, 2009). As penas são resíduos sólidos provenientes do abate de frangos, as quais necessitam de destino adequado. O destino mais comum para esse resíduo no Brasil é o uso como farinha de penas na alimentação de aves. Tal destino é quase exclusivo devido ao baixo interesse de outras áreas por esse resíduo do abatedouro de aves.

Portanto, além de elevar o lucro dos abatedouros avícolas e evitar a poluição ambiental, que poderia ser causada caso esses resíduos fossem descartados sem posterior reaproveitamento (Scapim et al., 2003), a utilização dos subprodutos de abatedouros como fonte alternativa de proteína e fósforo para rações reduz os custos da dieta, uma vez que esses produtos substituem parcial ou totalmente alguns ingredientes de custo expressivo, como farelo de soja e o fosfato bicálcico (Scheuermann et al., 2007).

A possível diminuição dos custos com nutrição seria muito vantajosa, uma vez que o custo da alimentação representa aproximadamente 70\% dos custos totais de produção. Portanto, objetivou-se avaliar o efeito da utilização de farinha de penas associada à enzima exógena protease em frangos de cortes de um a 32 dias de idade sobre a metabolizabilidade, pelo método da coleta total de excretas.

\section{MATERIAL E MÉTODOS}

O experimento foi realizado na Escola de Veterinária da Universidade Federal de Minas Gerais, localizada no município de Belo Horizonte - MG, no período de 10 de maio a 12 de junho de 2011. O projeto foi aprovado pelo
CEUA - Comitê de Ética no Uso de Animais da UFMG, protocolo 213/2010.

Utilizaram-se 336 pintos de corte, machos, $\mathrm{Cobb}^{\circledR}$, distribuídos ao acaso em quatro tratamentos, com sete repetições de 12 aves para coleta total de excretas na fase inicial de nove a 12 dias de idade. Na fase de crescimento, foram utilizadas as mesmas aves, no entanto duas aves de cada unidade experimental foram retiradas a fim de que todas as unidades contivessem 10 aves, totalizando 280 aves para a coleta total de excretas nesta fase, de 29 a 32 dias de idade.

Foram usados dois tipos de rações fareladas, de acordo com a fase de criação, ou seja, inicial (um a 21 dias) e crescimento ( 22 a 32 dias de idade), de acordo com os tratamentos. Para a formulação delas, foram utilizados os valores nutricionais dos ingredientes segundo as tabelas brasileiras de aves e suínos (Rostagno et al., 2011). Os níveis nutricionais das rações foram estabelecidos de acordo com Lara et al. (2008). A composição percentual das rações inicial e de crescimento, com seus respectivos níveis nutricionais calculados, encontra-se nas Tab. 1 e 2, respectivamente. A inclusão da farinha de penas foi de $2 \%$ na fase inicial e de $3 \%$ na fase de crescimento, independentemente dos tratamentos.

Os quatro tratamentos foram definidos pela inclusão de $0,05 \%$ da enzima protease ou pela não inclusão da enzima e pela valorização ou não da matriz nutricional da enzima. Foi feita a inclusão de farinha de penas em $2 \%$ na fase inicial e em $3 \%$ na fase de crescimento. Os tratamentos utilizados foram: T1 (controle positivo - ração basal, sem enzima), T2 (ração basal, com enzima), T3 (ração com enzima e matriz nutricional da enzima valorizada) e T4 (controle negativo - ração com matriz nutricional da enzima valorizada sem inclusão de enzima). A valorização da matriz nutricional da protease foi de $6,0 \%$ da proteína bruta e $45 \mathrm{kcal}$ de energia metabolizável.

As quantidades das rações oferecidas e as sobras foram pesadas semanalmente. As excretas foram coletadas na fase inicial e de crescimento duas vezes ao dia. O material recolhido foi utilizado para determinação de matéria seca, proteína bruta e extrato etéreo. As rações experimentais também passaram pelas mesmas análises, 
conforme técnicas descritas pelo Compêndio Brasileiro de Nutrição Animal (Compêndio..., 2005). As análises foram realizadas no laboratório de nutrição da Escola de Veterinária da UFMG.

Tabela 1. Composição percentual e valores nutricionais calculados das rações iniciais, de acordo com os tratamentos

\begin{tabular}{|c|c|c|c|c|}
\hline \multirow[b]{3}{*}{ Ingredientes (\%) } & \multicolumn{4}{|c|}{ Inicial } \\
\hline & A & $\mathrm{B}$ & $\mathrm{C}$ & $\mathrm{D}$ \\
\hline & Sem enzima & $\begin{array}{c}\text { Enzima } \\
\text { sem } \\
\text { valorização }\end{array}$ & $\begin{array}{l}\text { Enzima com } \\
\text { valorização }\end{array}$ & $\begin{array}{c}\text { Sem enzima } \\
\text { com } \\
\text { valorização }\end{array}$ \\
\hline Milho moído & 60,40 & 60,40 & 65,00 & 65,00 \\
\hline Farelo de soja 46 & 28,50 & 28,50 & 25,60 & 25,60 \\
\hline Óleo degomado de soja & 1,50 & 1,50 & - & - \\
\hline Farinha de carne $40 \%$ PB & 5,60 & 5,60 & 5,20 & 5,20 \\
\hline Farinha de penas & 2,00 & 2,00 & 2,00 & 2,00 \\
\hline Calcário & 0,10 & 0,10 & 0,32 & 0,32 \\
\hline Sal comum & 0,32 & 0,32 & 0,32 & 0,32 \\
\hline MHA-Ca & 0,42 & 0,42 & 0,39 & 0,39 \\
\hline Antioxidante & 0,10 & 0,10 & 0,10 & 0,10 \\
\hline L-Treonina & 0,13 & 0,13 & 0,12 & 0,12 \\
\hline L-Lisina & 0,42 & 0,42 & 0,43 & 0,43 \\
\hline Supl. vitamínico/mineral ${ }^{1}$ & 0,40 & 0,40 & 0,40 & 0,40 \\
\hline L- Triptofano & - & - & - & - \\
\hline Protease $^{2}$ & - & 0,05 & 0,05 & - \\
\hline Inerte & 0,05 & - & - & 0,05 \\
\hline Colina & 0,06 & 0,06 & 0,07 & 0,07 \\
\hline \multicolumn{5}{|l|}{ Níveis nutricionais } \\
\hline Proteína bruta (\%) & 22,50 & 22,50 & 22,50 & 21,30 \\
\hline EMA (kcal/kg) & 3000 & 3000 & 3000 & 2955 \\
\hline Cálcio (\%) & 0,94 & 0,94 & 0,94 & 0,95 \\
\hline Fósforo disponível (\%) & 0,46 & 0,46 & 0,46 & 0,45 \\
\hline Treonina dig. (\%) & 0,86 & 0,86 & 0,86 & 0,81 \\
\hline Lisina dig. (\%) & 1,32 & 1,32 & 1,32 & 1,25 \\
\hline Metionina dig. (\%) & 0,63 & 0,63 & 0,63 & 0,60 \\
\hline $\begin{array}{l}\text { Metionina + Cistina dig. } \\
(\%)\end{array}$ & 0,94 & 0,94 & 0,94 & 0,90 \\
\hline Sódio (\%) & 0,20 & 0,20 & 0,20 & 0,19 \\
\hline Valina dig. (\%) & 0,94 & 0,94 & 0,94 & 0,89 \\
\hline Triptofano dig. (\%) & 0,21 & 0,21 & 0,21 & 0,20 \\
\hline Colina (mg/kg) & 1518 & 1518 & 1518 & 1500 \\
\hline Arginina dig. & 1,36 & 1,36 & 1,36 & 1,27 \\
\hline
\end{tabular}

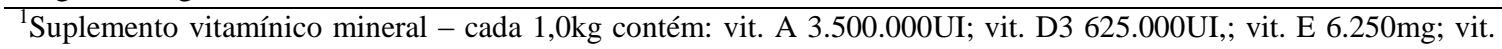
K3 750mg; vit. B1 500mg; vit. B2 1.250mg; vit. B6 1.000mg; vit. B12 $6.250 \mathrm{mcg}$; biotina 25mg; niacina 8.750mg; ácido fólico $250 \mathrm{mg}$; ácido pantotênico $3.000 \mathrm{mg}$; selênio $45 \mathrm{mg}$; iodo $175 \mathrm{mg}$; ferro $12.525 \mathrm{mg}$; cobre $2.500 \mathrm{mg}$; manganês 19.500; zinco $13.750 \mathrm{mg}$.

${ }^{2}$ Enzima exógena protease . 
Efeito da protease...

Tabela 2. Composição percentual e valores nutricionais calculados das rações de crescimento, de acordo com os tratamentos

\begin{tabular}{|c|c|c|c|c|}
\hline \multirow[b]{3}{*}{ Ingredientes $(\%)$} & \multicolumn{4}{|c|}{ Crescimento } \\
\hline & $\mathrm{A}$ & $\mathrm{B}$ & $\mathrm{C}$ & $\mathrm{D}$ \\
\hline & Sem enzima & $\begin{array}{c}\text { Enzima } \\
\text { sem } \\
\text { valorização }\end{array}$ & $\begin{array}{l}\text { Enzima com } \\
\text { valorização }\end{array}$ & $\begin{array}{c}\text { Sem enzima } \\
\text { com } \\
\text { valorização }\end{array}$ \\
\hline Milho moído & 68,65 & 68,65 & 74,5 & 74,5 \\
\hline Farelo de soja 46 & 20,00 & 20,00 & 15,8 & 15,8 \\
\hline Óleo degomado de soja & 1,80 & 1,80 & 0,09 & 0,09 \\
\hline Farinha de carne $40 \% \mathrm{~PB}$ & 4,40 & 4,40 & 4,50 & 4,50 \\
\hline Farinha de penas & 3,00 & 3,00 & 3,00 & 3,00 \\
\hline Calcário & 0,275 & 0,275 & 0,27 & 0,27 \\
\hline Sal comum & 0,35 & 0,35 & 0,33 & 0,33 \\
\hline MHA-Ca & 0,35 & 0,35 & 0,32 & 0,32 \\
\hline Antioxidante & 0,10 & 0,10 & 0,10 & 0,10 \\
\hline L-Treonina & 0,11 & 0,11 & 0,11 & 0,11 \\
\hline L-Lisina & 0,45 & 0,45 & 0,47 & 0,47 \\
\hline Supl. vitamínico/mineral ${ }^{1}$ & 0,40 & 0,40 & 0,40 & 0,40 \\
\hline L- Triptofano & 0,025 & 0,025 & 0,02 & 0,02 \\
\hline Protease $^{2}$ & - & 0,05 & 0,05 & - \\
\hline Inerte & 0,05 & - & - & 0,05 \\
\hline Colina & 0,04 & 0,04 & 0,04 & 0,04 \\
\hline \multicolumn{5}{|l|}{ Níveis nutricionais } \\
\hline Proteína bruta $(\%)$ & 19,50 & 19,50 & 19,50 & 18,20 \\
\hline EMA (kcal/kg) & 3122 & 3122 & 3122 & 3076 \\
\hline Cálcio (\%) & 0,84 & 0,84 & 0,84 & 0,85 \\
\hline Fósforo disponível (\%) & 0,41 & 0,41 & 0,41 & 0,42 \\
\hline Treonina dig. (\%) & 0,72 & 0,72 & 0,72 & 0,68 \\
\hline Lisina dig. (\%) & 1,11 & 1,11 & 1,11 & 1,04 \\
\hline Metionina dig. (\%) & 0,57 & 0,57 & 0,57 & 0,51 \\
\hline $\begin{array}{l}\text { Metionina + Cistina dig. } \\
(\%)\end{array}$ & 0,82 & 0,82 & 0,82 & 0,77 \\
\hline Sódio (\%) & 0,18 & 0,18 & 0,18 & 0,18 \\
\hline Valina dig. (\%) & 0,80 & 0,80 & 0,80 & 0,76 \\
\hline Triptofano dig. (\%) & 0,19 & 0,19 & 0,19 & 0,16 \\
\hline Colina (mg/kg) & 1217 & 1217 & 1217 & 1129 \\
\hline
\end{tabular}

${ }^{1}$ Suplemento vitamínico mineral - cada 1,0kg contém: vit. A 3.500.000UI; vit. D3 625.000UI; vit. E 6.250mg; vit. K3 750mg; vit. B1 500mg; vit. B2 1.250mg; vit. B6 1.000mg; vit. B12 $6.250 \mathrm{mcg}$; biotina 25mg; niacina $8.750 \mathrm{mg}$; ácido fólico 250mg; ácido pantotênico $3.000 \mathrm{mg}$; selênio $45 \mathrm{mg}$; iodo $175 \mathrm{mg}$; ferro $12.525 \mathrm{mg}$; cobre $2.500 \mathrm{mg}$; manganês 19.500; zinco $13.750 \mathrm{mg}$.

${ }^{2}$ Enzima exógena protease.

Com base nos resultados das análises de laboratório, bem como nos dados de consumo de ração e de produção de excretas, foram calculados os coeficientes de metabolizabilidade aparente da matéria seca (CMMS), da proteína bruta (CMPB) e do extrato etéreo (CMEE), conforme a seguinte fórmula:

Metabolizabilidade dos nutrientes $(\%)=\frac{\text { nutriente ingerido }(\mathrm{g})-\text { nutriente excretado }(\mathrm{g})}{\text { nutriente ingerido }(\mathrm{g})} \times 100$ 
O delineamento experimental para a determinação de metabolizabilidade dos nutrientes foi o inteiramente ao acaso, em arranjo fatorial 2x2 (com e sem enzima x com e sem valorização), sendo quatro tratamentos com sete repetições por tratamento. A gaiola foi considerada a repetição.

A normalidade e a homocedasticidade dos dados foram verificadas pelos testes de Lilliefors e Cochran, respectivamente. Os dados normais e homogêneos foram submetidos à análise de variância, e as diferenças entre as médias analisadas pelos testes $\mathrm{F}$ e de Tukey (Sampaio, 2002). As análises estatísticas foram realizadas por meio do programa SAEG 9.1 (2007).

\section{RESULTADOS E DISCUSSÃO}

$\mathrm{Na}$ fase inicial (um a 21 dias), o coeficiente de metabolizabilidade da matéria seca (CMMS) (Tab. 3) não foi afetado $(\mathrm{P}>0,05)$ pelos tratamentos utilizados.

Tabela 3. Coeficiente de metabolizabilidade da matéria seca (CMMS), das rações, em percentual, de acordo com os tratamentos, no período de nove a 12 dias de idade

\begin{tabular}{cccc}
\hline \multirow{2}{*}{ Enzima } & \multicolumn{2}{c}{ Valorização } & \multirow{2}{*}{ Média } \\
\cline { 2 - 3 } & Sem & Com & \\
\hline Sem & 73,05 & 74,21 & 73,63 \\
Com & 73,50 & 74,52 & 74,01 \\
Média & 73,27 & 74,36 & \\
\hline
\end{tabular}

Médias não seguidas de letras são semelhantes entre si pelo teste de $\mathrm{F}(\mathrm{P}>0,05)$. $\mathrm{CV}=2,7 \%$.

Resultados semelhantes para o CMMS foram encontrados por Olukosi et al. (2007), que não encontraram efeito da adição do complexo enzimático (xilanase, amilase e protease) sobre a metabolizabilidade da matéria seca. Entretanto, os autores observaram efeito negativo de valorização de cálcio, fósforo e energia metabolizável sobre o CMMS. Tal discrepância de resultados pode ter ocorrido porque os autores valorizaram cálcio e fósforo na dieta controle negativo e nas dietas com inclusão do complexo.

Garcia et al. (2000), ao avaliarem o efeito da suplementação enzimática (alfa-galactosidase, pectinase, celulase e protease) e da valorização (9\% e $7 \%$ da EM; $7 \%$ da PB; $5 \%$ da metionina, metionina+cistina e lisina) sobre a metabolizabilidade dos nutrientes, encontraram resultados semelhantes ao do presente estudo, ao não observarem diferenças significativas entre valores do CMMS entre os tratamentos utilizados.

Para a variável CMEE, a correlação entre enzima e valorização não foi significativa $(\mathrm{P}>0,05)$. As alterações nutricionais ocorridas em razão dos tratamentos não foram suficientes para alterar a metabolizabilidade do extrato etéreo das rações. (Tab. 4). Entretanto, Brito et al. (2006) observaram melhora na metabolizabilidade do extrato etéreo em $6 \%$ com a utilização de complexo multienzimático contendo protease. Contudo, esses pesquisadores não utilizaram controle negativo (dieta sem enzima com valorização) como método de comparação.

Tabela 4. Coeficiente de metabolizabilidade do extrato etéreo (CMEE), das rações, em percentual, de acordo com os tratamentos, no período de nove a 12 dias de idade

\begin{tabular}{cccc}
\multirow{2}{*}{ Enzima } & \multicolumn{2}{c}{ Valorização } & \multirow{2}{*}{ Média } \\
\cline { 2 - 3 } & Sem & Com & \\
\hline Sem & 79,07 & 79,75 & 79,41 \\
Com & 82,26 & 79,36 & 80,81 \\
Média & 80,67 & 79,56 & \\
\hline
\end{tabular}

Médias não seguidas de letras são semelhantes entre si pelo teste de $\mathrm{F}(\mathrm{P}>0,05)$. $\mathrm{CV}=5,1 \%$.

Para a variável CMPB, não houve interação entre os programas e recomendações nutricionais para as variáveis analisadas. Não houve efeito de enzima sobre o CMPB $(\mathrm{P}>0,05)$. Porém, independentemente da adição de enzima, os frangos de corte que consumiram ração com valorização da matriz nutricional apresentaram maior $(\mathrm{P} \leq 0,05)$ metabolizabilidade da proteína bruta (Tab. 5).

Observou-se um ganho compensatório, uma vez que os frangos que receberam menor aporte de nutrientes apresentaram melhor aproveitamento da proteína da dieta. 
Tabela 5. Coeficiente de metabolizabilidade da proteína bruta (CMPB), das rações, em percentual, de acordo com os tratamentos, no período de nove a 12 dias de idade

\begin{tabular}{cccc}
\multirow{2}{*}{ Enzima } & \multicolumn{2}{c}{ Valorização } & \multirow{2}{*}{ Média } \\
\cline { 2 - 3 } & Sem & Com & \\
\hline Sem & 62,51 & 65,79 & $64,15 \mathrm{~A}$ \\
Com & 61,48 & 65,22 & $63,35 \mathrm{~A}$ \\
Média & $61,99 \mathrm{~b}$ & $65,51 \mathrm{a}$ & \\
\hline
\end{tabular}

Médias seguidas de letras distintas, minúsculas na linha e maiúsculas na coluna, diferem entre si pelo teste de $\mathrm{F}(\mathrm{P} \leq 0,01)$. $\mathrm{CV}=4,9 \%$.

$\mathrm{Na}$ fase de crescimento, o coeficiente de metabolizabilidade da matéria seca (CMMS) (Tab. 6) não foi afetado pelos tratamentos propostos no presente estudo. Os frangos alimentados com dieta valorizada sem adição de enzima (controle negativo) apresentaram melhores resultados $(\mathrm{P} \leq 0,05)$ para $\mathrm{CMEE}$ e CMPB. Nos tratamentos com enzima, o melhor CMEE $(\mathrm{P} \leq 0,05)$ foi obtido com o tratamento sem valorização da matriz nutricional (over the top). Os melhores resultados $(\mathrm{P} \leq 0,05)$ para $\mathrm{CMPB}$ e CMEE foram obtidos com dieta valorizada sem enzima (controle negativo). O melhor CMEE $(\mathrm{P} \leq 0,05)$ foi obtido com adição enzimática na dieta sem valorização (over the top).

Tabela 6. Coeficiente de metabolizabilidade da matéria seca (CMMS), em percentual, das rações, de acordo com os tratamentos, no período de 29 a 32 dias de idade

\begin{tabular}{cccc}
\hline \multirow{2}{*}{ Enzima } & \multicolumn{2}{c}{ Valorização } & \multirow{2}{*}{ Média } \\
\cline { 2 - 3 } & Sem & Com & \\
\hline Sem & 77,03 & 76,98 & 77,00 \\
Com & 76,27 & 77,07 & 76,64 \\
Média & 76,65 & 77,02 & \\
\hline
\end{tabular}

Médias não seguidas de letras são semelhantes entre si pelo teste de $\mathrm{F}(\mathrm{P}>0,05)$. $\mathrm{CV}=1,2 \%$.

Os melhores resultados encontrados para CMEE foram para o controle negativo e over the top (Tab. 7), por apresentarem um efeito de maior aproveitamento em razão de um menor aporte de nutrientes e um possível efeito da enzima, respectivamente, melhorando a metabolizabilidade do extrato etéreo. Contudo, esse resultado difere do de Freitas et al. (2011), que encontraram melhores resultados de metabolizabilidade do extrato etéreo nos tratamentos que continham maiores níveis de proteína.

Tabela 7. Coeficiente de metabolizabilidade do extrato etéreo (CMEE), em percentual, das rações, de acordo com os tratamentos, no período de 29 a 32 dias de idade

\begin{tabular}{ccc}
\multirow{2}{*}{ Enzima } & \multicolumn{2}{c}{ Valorização } \\
\cline { 2 - 3 } & Sem & Com \\
\hline Sem & $81,28 \mathrm{bB}$ & $86,66 \mathrm{aA}$ \\
Com & $85,93 \mathrm{aA}$ & $73,24 \mathrm{bB}$
\end{tabular}

Médias seguidas de letras distintas, minúsculas na linha e maiúsculas na coluna, diferem entre si pelo teste Tukey $(\mathrm{P} \leq 0,05)$. $\mathrm{CV}=2,0 \%$.

Ocorreu interação entre os tratamentos para o CMPB. Entre os frangos alimentados com dietas sem adição de enzima, os que obtiveram melhores resultados de CMPB $(\mathrm{P} \leq 0,05)$ foram os frangos que receberam dieta com valorização (controle negativo). Nos tratamentos com enzima, não houve diferença significativa (P>0,05) nos resultados de CMPB quando se utilizaram dietas com e sem valorização. Para os frangos alimentados com dieta valorizada, os melhores resultados $(\mathrm{P} \leq 0,05)$ foram para as aves que receberam dieta sem enzima (controle negativo). Isso pode ter ocorrido devido à inibição de produção de enzimas endógenas nas aves dos tratamentos que receberam enzimas exógenas na ração. Entre os frangos alimentados com dieta sem valorização não houve diferença significativa $(\mathrm{P}>0,05)$ entre os tratamentos com e sem enzima (Tab. 8).

Tabela 8. Coeficiente de metabolizabilidade da proteína bruta (CMPB), em percentual, das rações, de acordo com os tratamentos, no período de 29 a 32 dias de idade

\begin{tabular}{ccc}
\hline \multirow{2}{*}{ Enzima } & \multicolumn{2}{c}{ Valorização } \\
\cline { 2 - 3 } & Sem & Com \\
\hline Sem & $62,69 \mathrm{bA}$ & $66,75 \mathrm{aA}$ \\
Com & $62,91 \mathrm{aA}$ & $61,86 \mathrm{aB}$ \\
\hline
\end{tabular}

Médias seguidas de letras distintas, minúsculas na linha e maiúsculas na coluna, diferem entre si pelo teste Tukey $(\mathrm{P} \leq 0,05)$. $\mathrm{CV}=4,2 \%$. 
Portanto, o tratamento controle negativo foi o que apresentou melhor aproveitamento da proteína bruta na fase de crescimento. Esse resultado pode ser explicado pelo fato de que frangos alimentados com menor aporte de nutrientes apresentam melhor capacidade de aproveitá-los. Contudo, esse resultado difere do de Freitas et al. (2011), que encontraram melhores resultados de metabolizabilidade da proteína bruta nos tratamentos que continham maiores níveis de proteína.

\section{CONCLUSÃO}

Nas condições em que foram realizados os experimentos, conclui-se que níveis reduzidos e enzima sem valorização melhoram os coeficientes de metabolizabilidade dos nutrientes na fase adulta de frangos de corte.

\section{AGRADECIMENTO}

À Fundação de Amparo à Pesquisa do Estado de Minas Gerais (Fapemig), pela concessão de recursos para publicação deste artigo científico.

\section{REFERÊNCIAS}

BRITO, C.O.; ALBINO, L.F.T.; ROSTAGNO, H.S. et al. Adição de complexo multienzimático em dietas à base de soja extrusada e desempenho de pintos de corte. Rev. Bras. de Zootec., v.35, p.457-641, 2006.

COMPÊNDIO Brasileiro De Nutrição Animal. 3.ed. São Paulo: Sindicato Nacional da Indústria de Alimentação Animal, 2005. 204p.

FREITAS, D.M.; VIEIRA, S.L.; ANGEL, C.R. et al. Performance and nutrient utilization of broilers fed diets supplemented with a novel mono component protease. J. Appl. Poult, v.20, p.322-334, 2011.
GARCIA, E.R.M.; MURAKAMI, A.E.; BRANCO, A.F. Suplementação enzimática em dietas contendo farelo de soja e soja integral extrusada e efeitos na digestibilidade dos nutrientes, fluxo ileal da digesta e performance de frangos de corte. Rev. Bras. Zootec., v.29, p.1414-1426, 2000.

HOLANDA, M.A.C. Avaliação nutricional da farinha de penas hidrolisada na alimentação de frangos de corte. 2009. 93f. Dissertação (Mestrado em Zootecnia) - Programa de PósGraduação em Zootecnia, Universidade Federal Rural de Pernambuco, Recife.

LARA, L.J.C.; BAIÃO, N.C.; ROCHA, J.S.R. et al. Influência da forma física da ração e da linhagem sobre o desempenho e rendimento de cortes de frangos de corte. Arq. Bras. Med. Vet. Zootec., v.60, p.970-978, 2008.

OLUKOSI, O.A.; COWIESON, A.J.; ADEOLA, O. Age-related influence of a cocktail of xylanase, amylase, and protease or phytase individually or in combination in broilers. Poult. Sci., v.86, p.77-86, 2007.

ROSTAGNO, H.S.; ALBINO, L.F.T.; DONZELE, J.L. et al. Tabelas Brasileiras para Aves e Suínos. Composição de alimentos e exigências nutricionais. Viçosa: UFV, 2011. $252 \mathrm{p}$.

SAMPAIO, I.B.M. Estatística aplicada à experimentação animal. 2.ed. Belo Horizonte: FEPMVZ, 2002. 265p.

SCAPIM, M.R.S; LOURES, E.G.; ROSTAGNO, H.S. et al. Avaliação nutricional da farinha de penas e de sangue para frangos de corte submetida a diferentes tratamentos térmicos. Acta Sci. Anim. Sci., v.25, p.91-98, 2003.

SCHEUERMANN, G.N.; ROSA, P.S.; BELLAVER, C. Farinhas de origem animal: vantagens e limitações do seu uso na alimentação de monogástricos. In: SIMPÓSIO CATARINENSE DE NUTRIÇÃO ANIMAL, 2007. Chapecó. Anais... Chapecó: UDESC, 2007. p.17. 